Research Article

\title{
Investigation of the Cross-Cutting Polycrystalline Diamond Compact Bit Drilling Efficiency
}

\author{
Chun-Liang Zhang $\mathbb{D}^{1},{ }^{1}$ Ying-Xin Yang, ${ }^{1,2}$ Hai-Tao Ren, ${ }^{1}$ Can Cai $\mathbb{D}^{1},{ }^{1}$ Yong Liu, \\ and Ming Yang ${ }^{1}$ \\ ${ }^{1}$ School of Mechatronic Engineering of Southwest Petroleum University, Chengdu, Sichuan 610500, China \\ ${ }^{2}$ State Key Lab of Oil and Gas Reservoir Geology and Exploitation, Chengdu, Sichuan 610500, China \\ Correspondence should be addressed to Chun-Liang Zhang; 201999010139@swpu.edu.cn
}

Received 30 July 2020; Revised 13 September 2020; Accepted 6 February 2021; Published 26 February 2021

Academic Editor: Tangbin Xia

Copyright (c) 2021 Chun-Liang Zhang et al. This is an open access article distributed under the Creative Commons Attribution License, which permits unrestricted use, distribution, and reproduction in any medium, provided the original work is properly cited.

\begin{abstract}
The parallel track scraping principle of conventional PDC bits largely limits the cutting efficiency and working life in deep formations. Cross-cutting polycrystalline diamond compact (PDC) bit may be an efficient drilling tool that increases the rockbreaking efficiency through both cross-cutting and alternate-cutting modes of the PDC cutter. The motion track equation of the cross-cutting PDC bit was derived by using the compound coordinate system, and the motion track was analyzed. Meanwhile, through the unit experiment and discrete element simulation, the cutting force, volume-specific load, and crack propagation were analyzed under different cutting modes. Through establishing a nonlinear dynamic model of the bit-rock system, the speed-up mechanism of the novel bit was analyzed based on rock damage, rock stress state, and motion characteristic of the bit during the rock-breaking process. Compared with unidirectional cutting, cross-cutting produces less cutting force, more brittle fracture, and a greater decrease of formation strength. The novel PDC bit can put more rock elements into a tensile stress condition than a conventional PDC bit, and the plastic energy dissipation ratio of the cross-cutting PDC bit is lower while the damage energy consumption ratio is higher than they are for conventional bits, which is beneficial to increasing the ratio of fracture failure and improving rock-breaking efficiency. Laboratory drilling tests show that the cross-cutting PDC bit can create mesh-like bottomhole features. Drilling contrast experiments show that a mesh-like bottom-hole pattern can be obtained by using the cross-cutting PDC bit, of which the ROP is obviously higher than that of the conventional bit when drilling in sandstone or limestone formation. Meanwhile, the influence of deviation angle, weight on bit, and rock properties on cutting efficiency of the crosscutting PDC bit are studied.
\end{abstract}

\section{Introduction}

Currently, the exploration and development of oil and gas continue to develop toward deep wells and ultradeep wells [1]. As a consequence, deep well drilling technology plays an increasingly greater role in this area [2]. As the well depth increases, the hardness and abrasiveness of rock become stronger, while the drillability is poorer [3], and low penetration rate and high energy consumption become the main factors. Against the backdrop of sluggish international oil prices, to shorten the drilling cycle and reduce cost, it is imperative to raise the drilling speed of the drill in deep formation. Generally, the compressive stress of rock is much higher than its tensile stress [4]. Polycrystalline diamond compact (PDC) bits break rock by means of shearing, which makes them much more efficient than cone bits in either soft or hard formations. Nevertheless, when drilling in deep formations of poor drillability, even PDC bits cannot achieve satisfactory performance. For existing PDC bits, cutter technology and bit structure are two of the key factors limiting rockbreaking efficiency [5-7]. In recent years, PDC technology has greatly progressed, making up for the weakness in the bit structure to some extent [8]. 
It is a shared goal for researchers and manufacturers to achieve better synergy between cutter technology and bit structure. Numerous developments have appeared in the past few years [9-12]: Smith Company launched an axeridge-type bit that incorporates three rock damage mechanisms, including cutting, extrusion, and turning over, and, up to now, total drilled footage amounts to $60,960 \mathrm{~m}$. Shear Bits Company proposed a composite bit (PEXUS) that combines two structure units slicing and shearing to fracture and intrude the rock, increasing the penetration rate in hard strata. Baker Hughes Company proposed a cone-PDC hybrid bit that combines the advantages of cutter extrusion and PDC cutter shear failure. China Deep-Fast Company designed a module bit, which, through the composite design of the cutting unit, can maintain a high specific pressure of the clipping unit while drilling; this bit has been proven to be effective in the application in hard strata. These new technologies are all helpful in improving rock-breaking efficiency; however, further progress remains to be achieved. Besides, the continuous working of PDC cutters and the concentrically ringed motion trail remain the same [13]. In addition, there is much research on the rock-breaking mechanism of bit. Rojek et al. analyzed the rock-breaking process of the cutter with a discrete element model [14]. Huff et al. from Sandia National Laboratories conducted a large number of single-cutter cutting experiment to reveal the variation regularity of the cutting force affected by the changing back rake angle of the cutter [15]. Zeuch, Swenson and Finger et al. researched the breaking condition of the rock through a single-cutter cutting experiment [16, 17]. Zhai et al. from China University of Petroleum conducted a series of research on the cutting load variation regularity of individual PDC cutter [18]. However, these studies are mainly focused on smooth bottom-hole cutting, and there are a few reports on nonsmooth bottom-hole cutting. This paper discusses the rock-breaking efficiency of the new type bit with cross-scraping principle by studying the rock stress field law, energy consumption law, and the working mechanics of the new bit under different conditions. The numerical simulation and experimental test complement each other and confirm each other.

Cross-cutting PDC bit that can realize alternate work in rock breaking and form retiform bottom-hole patterns potentially leading to increased rock-breaking efficiency and sustainable drilling capability $[19,20]$. The motion track equation of cross-cutting PDC bit was derived by using the compound coordinate system. Through the unit experiment and discrete element simulation, the cutting force, volumespecific load, and crack propagation were analyzed under different cutting modes. Via bit-rock system nonlinear dynamic model, the rock-breaking process of the crosscutting PDC bit is simulated, then the efficiency increasing mechanism is analyzed. Through conducting indoor experiments, we compare the rock-breaking efficiency of, respectively, cross-cutting and conventional types of bits and analyze how different elements of the cross-cutting PDC bit influence rock-breaking efficiency.

\section{The Operating Principle of the Cross-Cutting PDC Bit}

2.1. The Construction Features of Cross-Cutting PDC Bit. The cross-cutting PDC bit combines dynamic and static cutting structures, giving full play to the advantages of PDC rock breaking. As shown in Figure 1(a), the scraping-wheel and the PDC bit constitute the cross-cutting PDC bit cutting structure; the fixed cutting structure consists of a blade and PDC cutters. The deviation angle $\alpha$ is determined by the central arm length $c$ and the offset axis $s$ : $\alpha=\tan ^{-1}(s / c)$, as shown in Figure 1(b). The value range of the deviation angle is $40^{\circ} \leq \alpha \leq 90^{\circ}$.

2.2. Motion Track of Cross-Scraping PDC Bit. The analysis on the motion track of the cutter is conducive to understanding the interaction process between the cutter and rock and provide a reference for the optimization design of crossscraping PDC bit. The motion track of the fixed cutter on the drill body is a concentric-circle, which is not analyzed here. This paper only analysis the motion track of the cutter and the cross-scraping PDC bit.

According to the structure characteristics of crossscraping PDC bit, the motion of cutter on a scraping-wheel (hereinafter referred to as wheel cutters) includes: rotation about the scraping-wheel axis, revolution about the bit axis, and translation along the drilling direction. Therefore, the wheel cutter is a spatial compound motion. In consideration of the complicated motion of the wheel cutter, the compound coordinate systems are established. The compound coordinate systems include bit coordinate system, scrapingwheel coordinate system, and wheel cutter coordinate system. As illustrated in Figure 2(a), a certain point $K$ in the bit could be represented by the coordinates $\left(R_{K}, \theta_{K}, H_{K}\right)$, where $R_{K}$ is the polar radius, $\theta_{K}$ is the polar angle, and $H_{K}$ is the vertical height of the point. Meanwhile, in order to facilitate digital calculation, a rectangular coordinate system of bit is established. To analyze the location-relation between the wheel cutter and scraping-wheel, both rectangular and cylindrical coordinate systems of the scraping-wheel are established. The feature point $Q$ on the scraping-wheel can be expressed as $\left(x_{i}, y_{i}, z_{i}\right)$ and $\left(\lambda_{Q}, \lambda_{Q}, \lambda_{Q}\right)$, as shown in Figure 2(b).

In order to simplify the motion equation of the cutter, the feature point $Q$ of the cutter is set at the central origin of the cutter working plane. Then, the coordinates of the wheel cutter in the rectangular coordinate system can be expressed as follows:

$$
\left\{\begin{array}{l}
x_{i}=r \cos \varepsilon, \\
y_{i}=r \sin \varepsilon, \\
z_{i}=0 .
\end{array}\right.
$$

Then, the coordinates $\left(x_{i}, y_{i}, z_{i}\right)$ are transformed into the rectangular coordinate system of the bit by the translation and rotation transformation, obtaining 


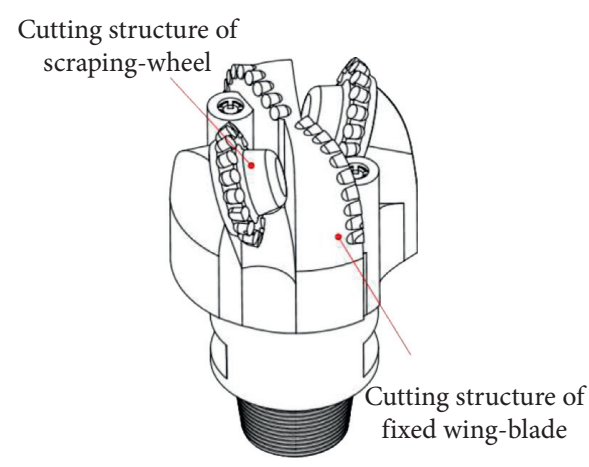

(a)

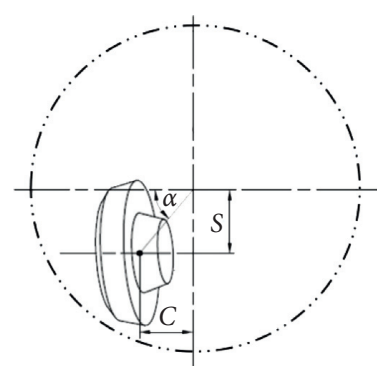

(b)

FIGURE 1: Structure and bottom-hole pattern of the cross-cutting PDC bit. (a) Cross-cutting PDC bit, (b) Angular deflection of the scrapingwheel.

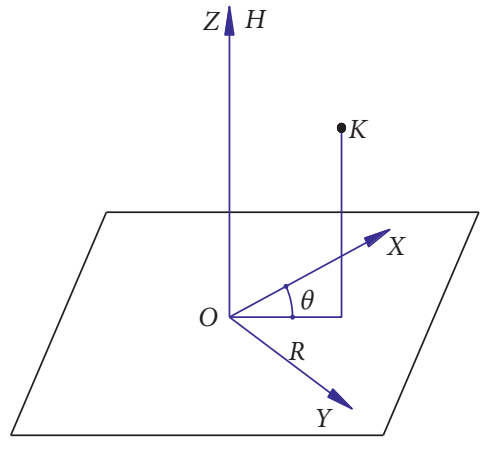

(a)

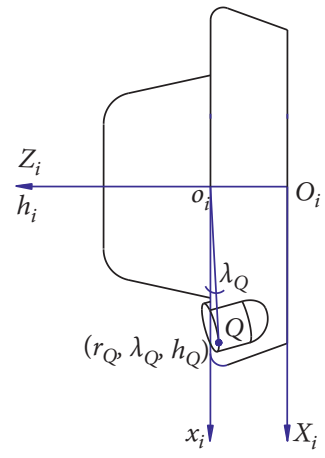

(b)

FIgure 2: Coordinate systems of the scraping-wheel PDC bit. (a) Coordinate system of the bit body and (b) coordinate system of the scraping-wheel.

$$
\left(\begin{array}{c}
X=-\left(y_{i}+S\right) \sin \theta_{0}+\left(z_{i} \cdot \cos \beta-x_{i} \cdot \sin \beta+C\right) \cos \theta_{0}, \\
Y=-\left(y_{i}+S\right) \cos \theta_{0}-\left(z_{i} \cdot \cos \beta-x_{i} \cdot \sin \beta+C\right) \sin \theta_{0}, \\
Z=z_{i} \sin \beta+x_{i} \cos \beta+H_{0} .
\end{array}\right)
$$

Suppose point $Q$ is a moving point, which changes with the rotation of the scraping-wheel, and the speed ratio of bit is $i$. when the scraping-wheel rotates angle $\varepsilon$, the bit rotates angle $\varepsilon / i$, and the footage per turn of the bit is $f$; the new coordinates are obtained

$$
\left\{\begin{aligned}
X_{T}= & {\left[-\left(y_{i}+S\right) \sin \theta_{0}+\left(z_{i} \cdot \cos \beta-x_{i} \cdot \sin \beta+C\right) \cos \theta_{0}\right] \cos \left(\frac{\varepsilon}{i}\right), } \\
& +\left[-\left(y_{i}+S\right) \cos \theta_{0}-\left(z_{i} \cdot \cos \beta-x_{i} \cdot \sin \beta+C\right) \sin \theta_{0}\right] \sin \left(\frac{\varepsilon}{i}\right), \\
Y_{T}= & {\left[\left(y_{i}+S\right) \sin \theta_{0}-\left(z_{i} \cdot \cos \beta-x_{i} \cdot \sin \beta+C\right) \cos \theta_{0}\right] \sin \left(\frac{\varepsilon}{i}\right), } \\
& +\left[-\left(y_{i}+S\right) \cos \theta_{0}-\left(z_{i} \cdot \cos \beta-x_{i} \cdot \sin \beta+C\right) \sin \theta_{0}\right] \cos \left(\frac{\varepsilon}{i}\right), \\
Z_{T}= & z_{i} \sin \beta+x_{i} \cos \beta+H_{0}+\left(\frac{\varepsilon}{2 \pi \cdot i}\right) f .
\end{aligned}\right.
$$


Equation (3) is the motion track equation of the wheel cutter. As illustrated in Figure 3, the calculation results show that the motion track of the wheel $\mathrm{c}$ utter is a complicated spatial curve. In general, the cutter in the outer radial area of the bit is easy to wear and the rock-breaking efficiency is low. Therefore, when designing a cross-scraping PDC bit, the scraping-wheel cutting structure is set in the outer radial area of the bit. As illustrated in Figure 4, the cooperating area of scraping-wheel cutting structure and fixed cutting structure lies between points en and ex.

The setting of the big deviation angle breaches the pure rolling conditions of the scraping-wheel, making it roll at low speed, realizing alternate work of the cutters on the scraping-wheel and the scraping bottom rock in the spiraling path. And the cutters on the fixed cutting structure still scrape rock in a concentric ring trail. With the two trails coinciding, cross-cutting is achieved, and uneven retiform bottom pattern is formed, as shown in Figure 5. Compared with the conventional PDC bit, cross-cutting PDC bit has the following main advantages: (1) the energy consumption of cross-scraping rock breaking is low; (2) the alternative working of the wheel cutter is conducive to cooling and reducing thermal wear; (3) the cutter is more likely to invade into rock and improve rock-breaking efficiency.

\section{Analysis on Rock-Breaking Efficiency of the Cutter Cross-Cutting}

The cutting force and volume-specific load of the cutter can be directly and truly obtained by unit rock-breaking experiment, which is a common technical method to study rock-breaking mechanism. Figure 6 shows the cutting experiment process under different cutting modes. Under unidirectional cutting (the conventional bit), the cutter continuously contacts with the rock to form a continuous protrusion. The rock surface with isolated rock protrusion is formed in the cross-scraping process.

Figure 7(a) shows the time-variation of cutting force of unidirectional cutting and cross-cutting. The figures indicate that the cutting force during unidirectional cutting is larger than that during cross-cutting. As illustrated in Figure 7(b), with the same experimental parameters, the volume-specific load of cross-cutting is smaller than that of unidirectional cutting. Since cross-cutting makes a rugged pattern in the rock, high-stress concentration and microcracks will be formed within the rock protrusions near the cross area, when cutters contact this area, the rock-breaking ratio of tensile stress increases, making the cutting load smaller.

Under different cutting modes, the generation process of rock debris is simulated by using the discrete element method. The formation of rock debris can be divided into three stages [16]: crack initiation, crack propagation, and crack coalescence. Under unidirectional cutting, the crack develops to the free surface of the rock at a large shear angle, and the rock is refractured obviously, as shown in Figure 8(a). However, in the case of cross scraping, the cracks run through the whole rock protrusion at a very small shear angle without obvious plastic deformation, as shown in Figure 8(b). Therefore, cross-cutting is an efficient rock-breaking method saving both force and power.

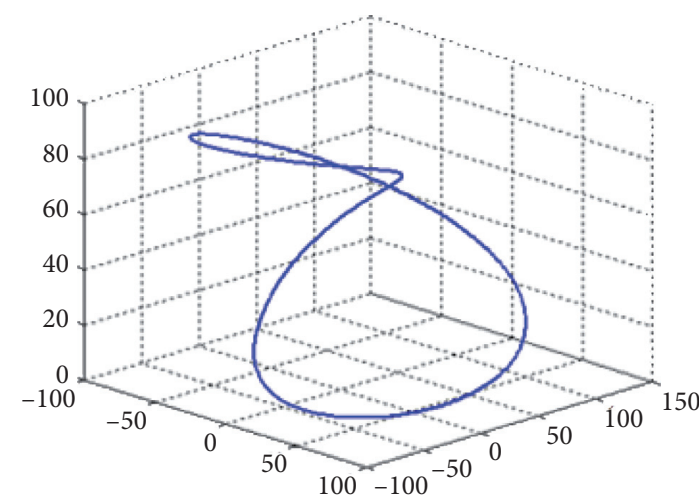

Figure 3: Motion track of the wheel cutter.

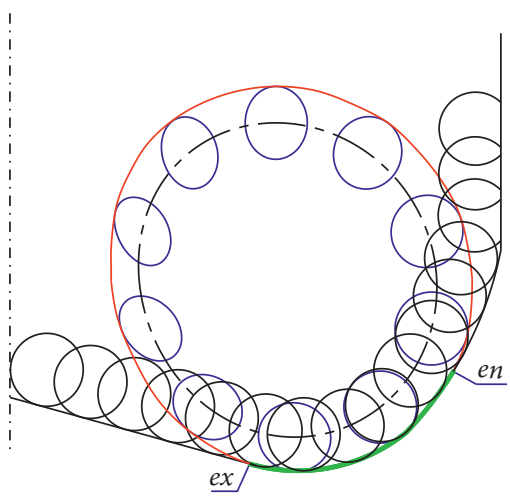

FIGURE 4: Covering graph of the bit.

\section{Bit-Rock System Dynamics Simulated Analysis}

4.1. Constitutive Relation and Rock Failure Criterion. Rock is a granular material, so when subjected to shear forces, the grains expand [21, 22]. The Drucker-Prager (DP) strength criterion not only considers the influence that the intermediate principal stress has on yield characteristics but also reflects the expansion characteristics caused by cutting and is widely applied in studies on rock-breaking [23-25]. The D-P rule applied to the normal stress $\sigma_{\text {oct }}$ and shearing stress $\tau_{\text {oct }}$ of a regular octahedron gives

$$
\tau_{\mathrm{oct}}=\tau_{0}+m \sigma_{\mathrm{oct}},
$$

where

$$
\begin{aligned}
& \left\{\begin{array}{l}
\tau_{\mathrm{oct}}=\frac{1}{3} \sqrt{\left(\sigma_{1}-\sigma_{2}\right)^{2}+\left(\sigma_{2}-\sigma_{3}\right)^{2}+\left(\sigma_{3}-\sigma_{1}\right)^{2}}, \\
\sigma_{\mathrm{oct}}=\frac{1}{3}\left(\sigma_{1}+\sigma_{2}+\sigma_{3}\right), \\
m=-\sqrt{6 \delta}, \tau_{0}=\frac{\sqrt{6}}{3} k,
\end{array}\right. \\
& \delta=\frac{2 \sin \varphi}{\sqrt{3}(3-\sin \varphi)}, \\
& K=\frac{6 c \cos \varphi}{\sqrt{3}(3-\sin \varphi)} \text {. }
\end{aligned}
$$




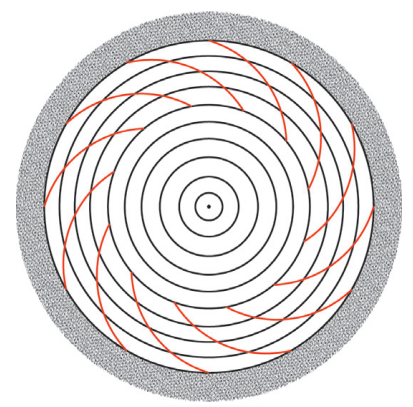

(a)

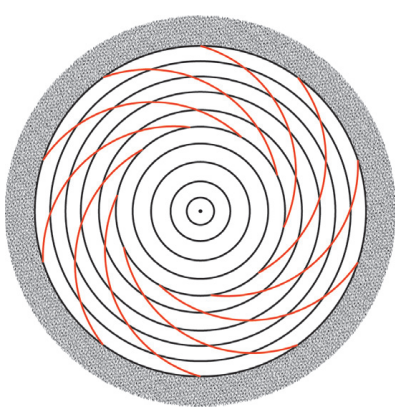

(b)

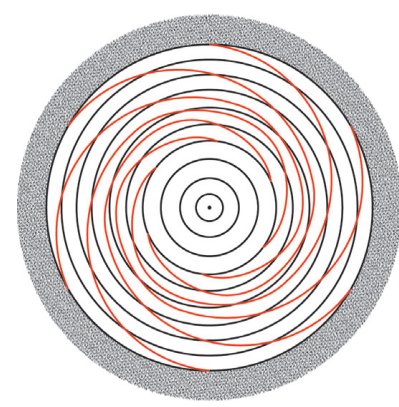

(c)

Figure 5: Bottom-hole patterns under different deviation angles.

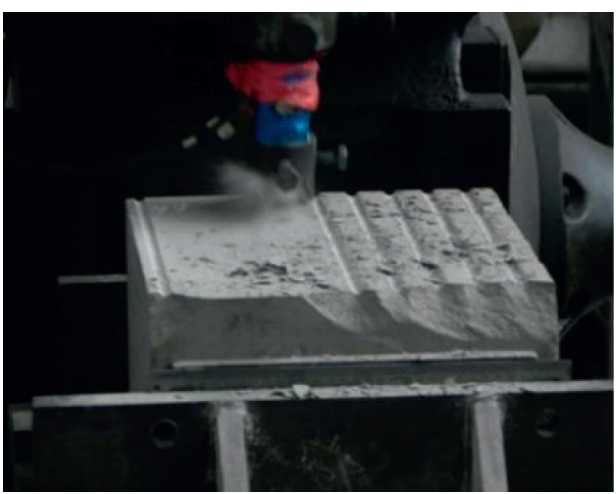

(a)

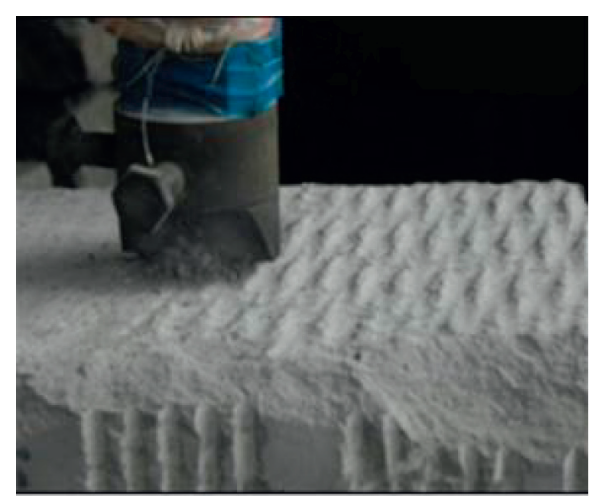

(b)

FIGURE 6: Cutting process under different cutting modes. (a) Unidirectional cutting, (b) Cross-cutting.

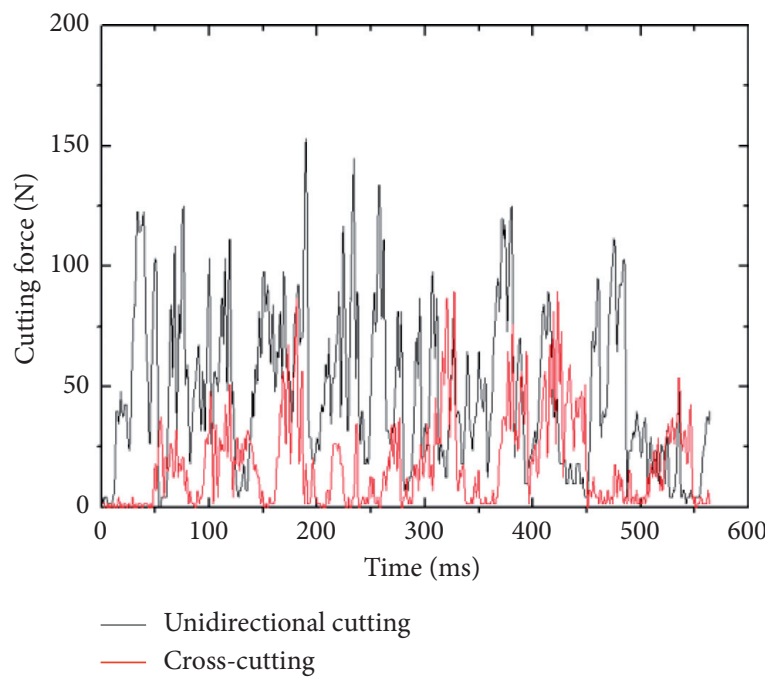

(a)

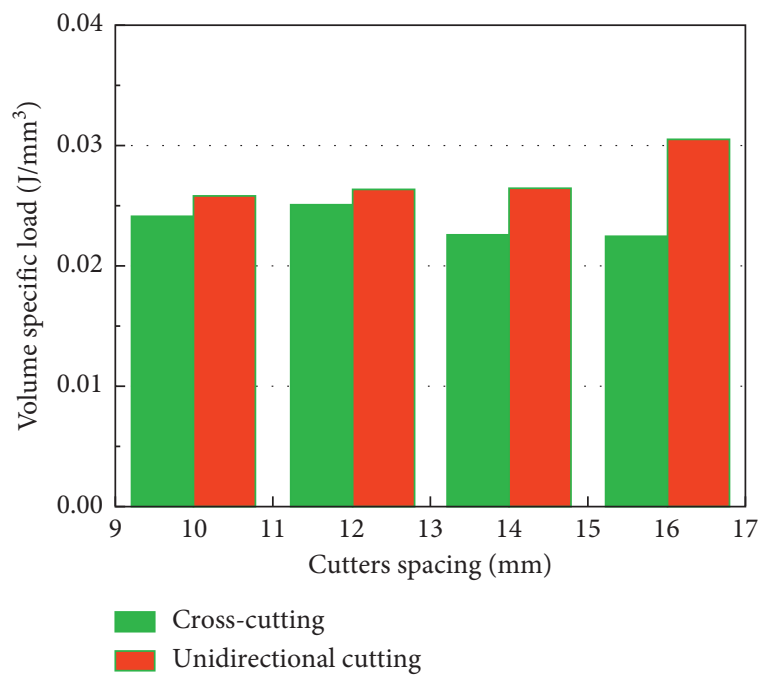

(b)

Figure 7: Change regulation of cutting force and volume-specific load under different cutting modes. (a) Cutting force and (b) volumespecific load.

In these expressions, $\sigma_{1}, \sigma_{2}$, and $\sigma_{3}$ are the main rock stresses and $k$ and $\delta$ are internal friction angle relevant parameters of material cohesive forces $c$ and $\varphi$.
In the rock-breaking process, when damage begins, we use the equivalent elastic displacement $\bar{u}^{p l}$ to describe the damage development of the material. When the initial 

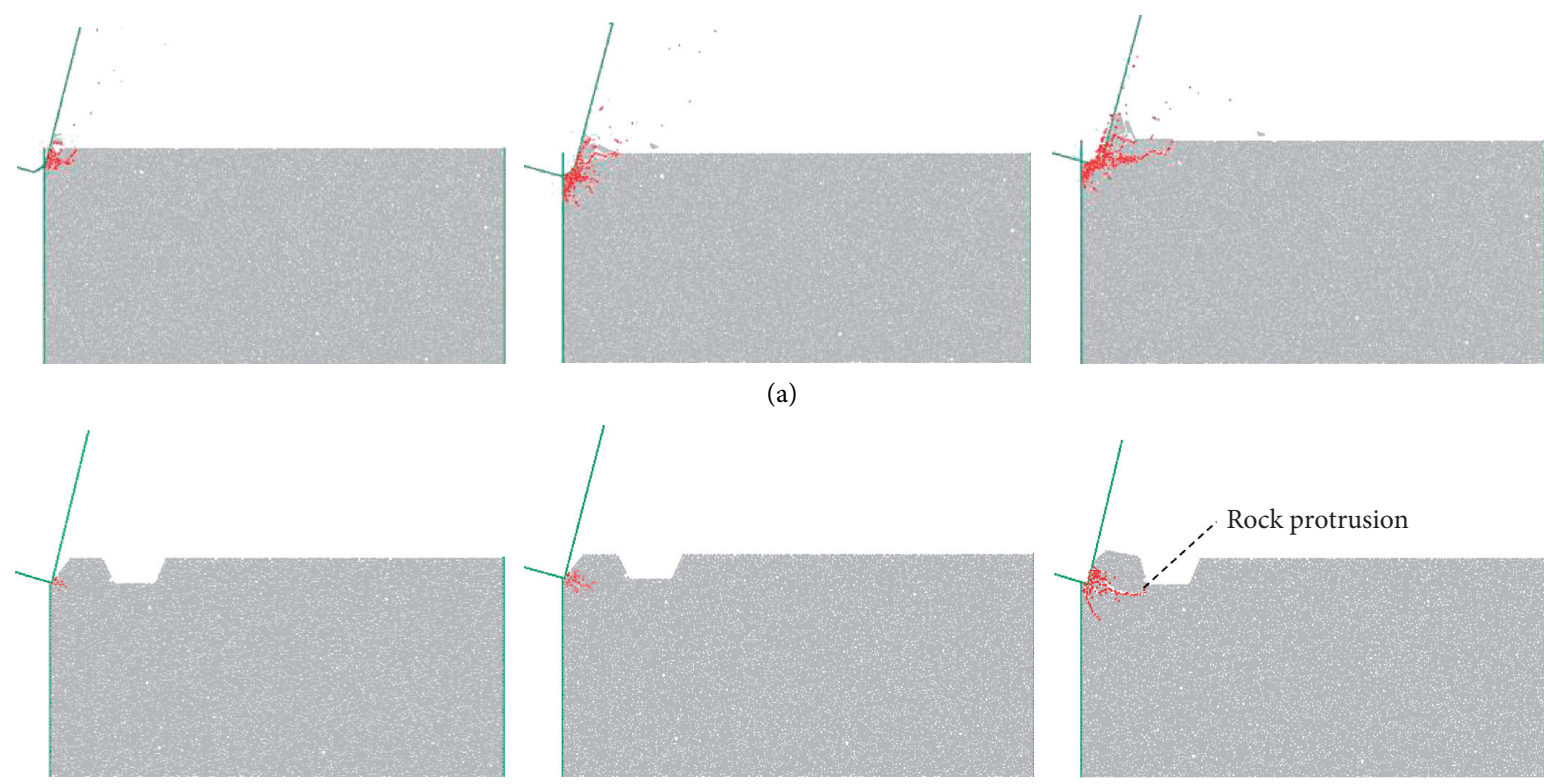

(a)
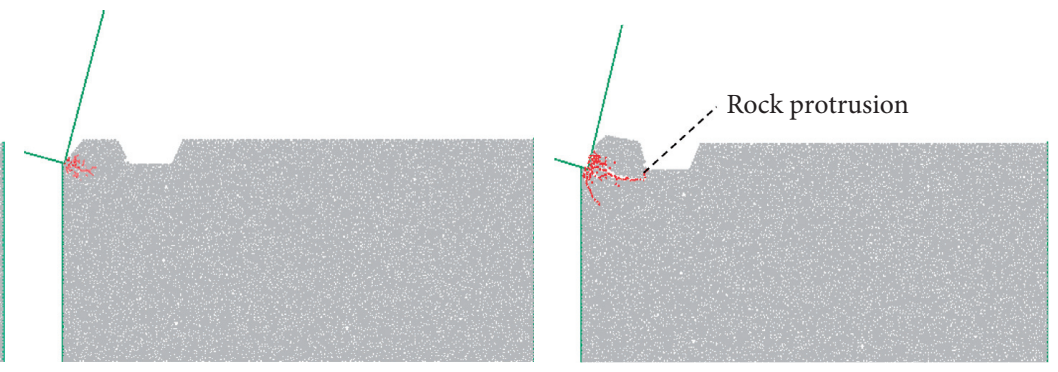

(b)

FIGURE 8: Crack propagation of rock under different cutting modes. (a) Unidirectional cutting and (b) cross-cutting.

damage condition is met, the equivalent elastic displacement $\bar{u}^{p l}$ will satisfy

$$
\dot{\bar{u}}^{p l}=L \dot{\bar{\varepsilon}}^{p l}
$$

Using equivalent elastic displacement to set the linear damage progress variable, we can assign $\bar{u}^{p l}$ at the complete failure point. When $\bar{u}^{p l}=\bar{u}_{f}^{p l}$, the material hardness drops to a minimum and $d=1$, and the variable increases according to the following expression:

$$
\dot{d}=\frac{L \dot{\bar{\varepsilon}}^{p l}}{\bar{u}_{f}^{p l}}=\frac{\dot{\bar{u}}^{p l}}{\bar{u}_{f}^{p l}} .
$$

4.2. Bit-Rock System Interaction Model Building. For ease of establishing and solving the bit-rock system model, the model was simplified as follows: (1) Each cutter was treated as a rigid body. (2) The bottom-hole rock was placed in the far-field region of the borehole. (3) The influence of temperature and confining pressure on the rock-breaking process were ignored.

In building, respectively, nonlinear dynamics interaction models of the cross-cutting PDC bit and the conventional bit, we need to discuss the stress state of the rock during the interaction process as well as the motion characteristics of the bit. Through finite element software (ABAQUS), we constructed, respectively, nonlinear dynamics models of a cross-cutting PDC bit with a $215.9 \mathrm{~mm}$ diameter and a conventional PDC bit; the rock was dispersed with an eightnode select-reduced unit (C3D8R) controlled by a sand clock, as shown in Figures 9 and 10. The stratum lithology was Beibei limestone, whose basic properties are given in Table 1 .

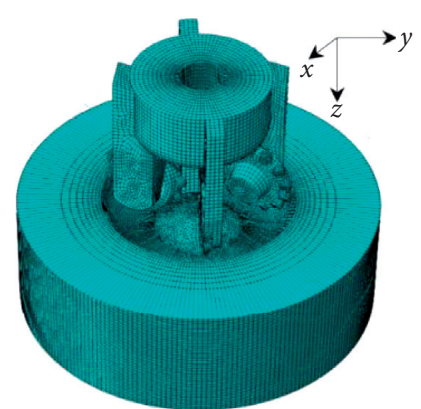

FIgURE 9: The finite element model of the novel PDC bit-rock.

4.3. Results and Discussion. Based on the finite element model and controlling methods set above, we conducted dynamic response analyses of the two bit-rock systems. Figure 11 shows the bottom patterns of different stages after the cross-cutting PDC bit broke the rock. In the initial stage of drilling, the bit touches the rock under the drill pressure, and the rock under the bit is heavily stressed and damaged. As the weight on bit (WOB) increases, the wheel cutters invade the rock and scrape in a spiral trail and the cutter on the blade scrape in a concentric-circle track, increasing the stress on rock unit until its breaking limit, at which point failure occurs and the wellbore forms.

Under the effect of the cross-cutting PDC bit, a number of rock elements are under a tensile stress condition (positive), especially the cross areas of the two tracks where the tensile stress value is high, as shown in Figure 12. Despite the fact that, as the conventional bit proceeds, the tensile stress on the rock element exists too, the value is small and is small in proportion, and many rock elements are under the condition of compressive stress. For rock, the tensile strength is much lower than the compressive strength, which 


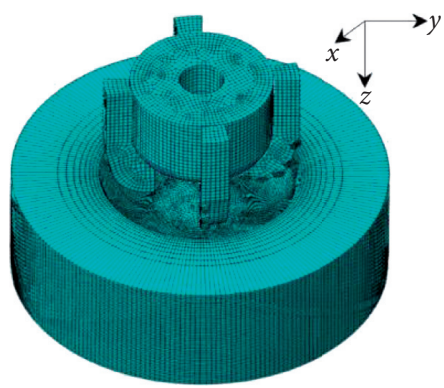

Figure 10: The finite element model of the conventional PDC bit-rock.

TABLE 1: Basic mechanical parameters of the rock.

\begin{tabular}{|c|c|c|c|c|c|c|}
\hline Rock sample & $\begin{array}{c}\text { Elastic modulus } \\
(\mathrm{GPa})\end{array}$ & $\begin{array}{l}\text { Poisson's } \\
\text { ratio }\end{array}$ & $\begin{array}{c}\text { Compressive strength } \\
(\mathrm{MPa})\end{array}$ & $\begin{array}{l}\text { Tensile strength } \\
(\mathrm{MPa})\end{array}$ & $\begin{array}{l}\text { Shear strength } \\
(\mathrm{MPa})\end{array}$ & $\begin{array}{c}\text { Friction angle } \\
\left({ }^{\circ}\right)\end{array}$ \\
\hline $\begin{array}{l}\text { Beibei } \\
\text { limestone }\end{array}$ & 31.2 & 0.171 & 105.951 & 6.578 & 17.72 & 43.62 \\
\hline
\end{tabular}

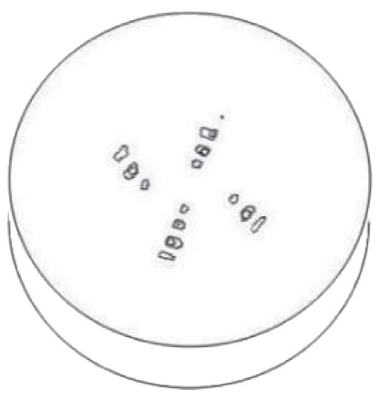

(a)

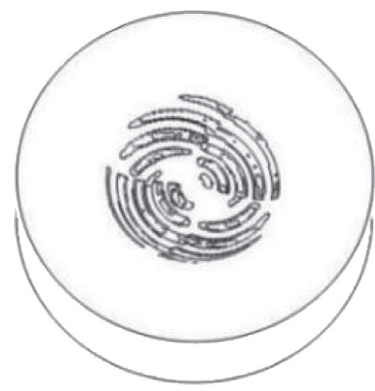

(b)

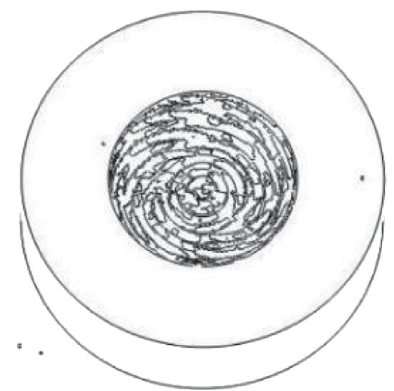

(c)

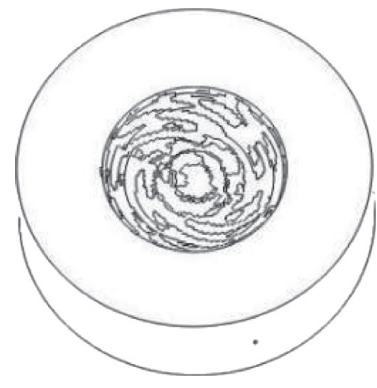

(d)

FIgURE 11: Bottom-hole patterns in different times. (a) $t=0.05 \mathrm{~s}$, (b) $t=0.6 \mathrm{~s}$, (c) $t=2 \mathrm{~s}$, and (d) $t=4 \mathrm{~s}$.
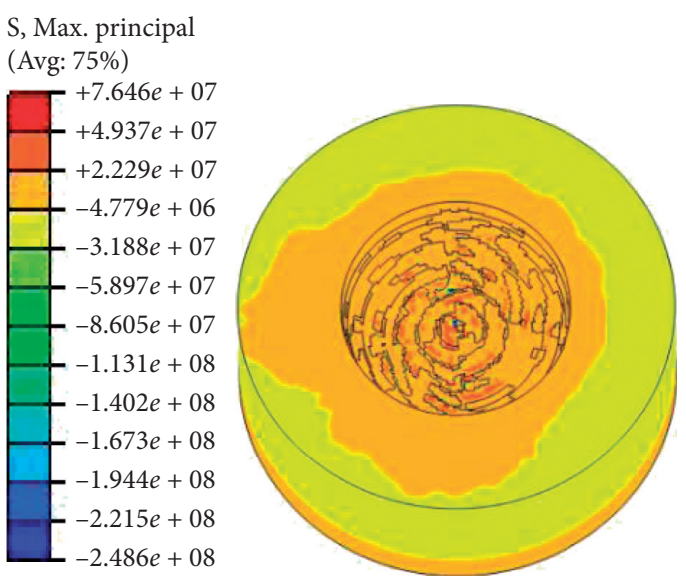

(a)

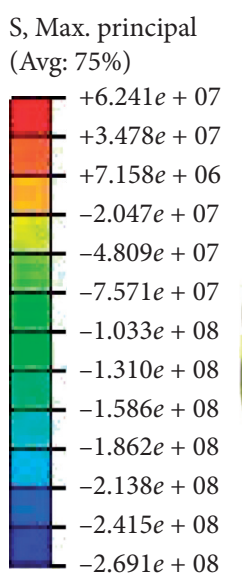

(Avg: $75 \%$ )

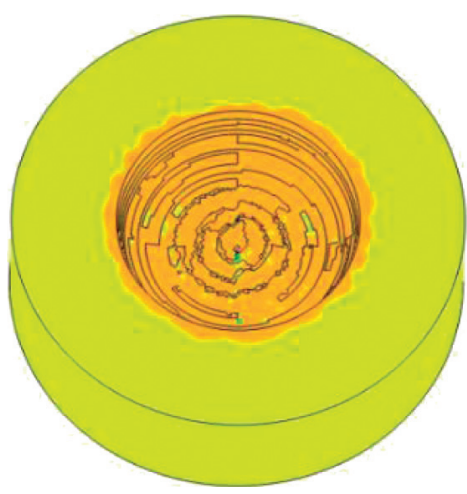

(b)

FIGURE 12: Maximum principal stress of rock by different bit. (a) Cross-cutting PDC bit. (b) Conventional PDC bit.

is why cross-cutting PDC bits have a much higher rockbreaking efficiency than do conventional PDC bits. Moreover, the rock on the sidewall is under the condition of tensile stress because of the expansion caused by the interaction of the confining pressure and the overburden pressure. 
The speeds of the two drilling bits in the drilling process are different, especially at the beginning as the bottom initially forms (Figure 13). The cross-cutting bit combines dynamic and static structures, and speed fluctuation can be higher than those of conventional bits. As the acceleration curve in Figure 14 shows, during drilling, the vertical amplitudes of the two kinds of bits are basically the same. Although a dynamic cutting structure is installed on the cross-scraping PDC bit, the vibration is not large, which is conducive to prolong the service life of the bit.

In rock breaking, the cross-cutting PDC bit cross-cuts the bottom rock, causing more damage to the rock; in other words, the damage energy consumption proportion of the cross-cutting bit is higher than that of the conventional one, as shown in Figure 15. Figure 16 shows different plastic energy dissipation rates for the two types of bits, and it is obvious that the conventional PDC bit consumes more plastic energy than does the cross-cutting bit. The reason for this difference is that the cross-cutting feature of the crosscutting bit causes an uneven bottom rock surface, and the proportion of brittle fracture increases when breaking bottom rock with a more free surface. The experimental results show that the better offset angle range of the new bit is $70^{\circ} \sim 90^{\circ}$.

\section{Experiment}

5.1. Development of the Variable-Parameter Experimental Bit. The numerical simulation can give qualitative assessments of the rock-breaking mechanism of the new type of bit from the motion state of the new PDC bit, the stress state of the rock, and the ratio of energy consumption, but it is not easy to analyze the bottom-hole mode and the working load, which requires a change of structural parameters of the test bit. The overall design of the bit includes scraping-wheel 1, bit leg 2 , bit leg base 3 , blade 4 , blade base 5 , and bit base 6 , as shown in Figure 17. Bit leg base 3 can achieve transversal and longitudinal movement in bit base 6 , and the deviation angle of the scraping-wheel can be adjusted by changing the cone offset as well as the central arm length of scraping-wheel 1. Altitude control of blade 4 can be achieved by using wedge blocks 7. The assembly diagram of the full-hole drilling experimental bit, as well as the replaceable scraping-wheel and blade, is shown in Figure 18. As the structural parameters of the corresponding new PDC bit vary, the locking structure is designed. When the locking structure is locked, the novel bit becomes the corresponding fixed-tooth PDC bit. Two grooves are machined separately at the end face of the bearing and the front face of the blade. Two bosses are designed at the axle head, and these can lock the blades after installation; the test bit equals a conventional fixed-tooth PDC bit when the blades are locked.

5.2. Experimental Equipment and Methods. The purpose of the drilling experiment is to analyze the shaft bottom pattern of the cross-cutting bit, compare the rock-breaking efficiency of the cross-cutting PDC bit to that of the conventional one, and study the influence rule of major elements

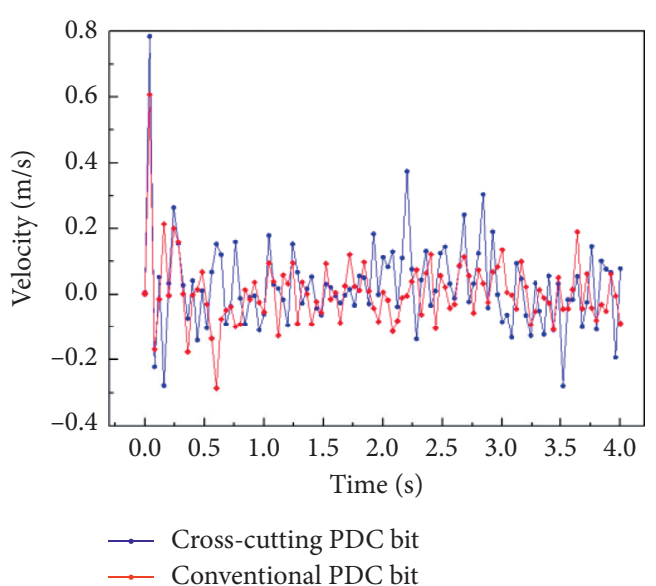

FIgURE 13: Velocity response along the drilling direction.

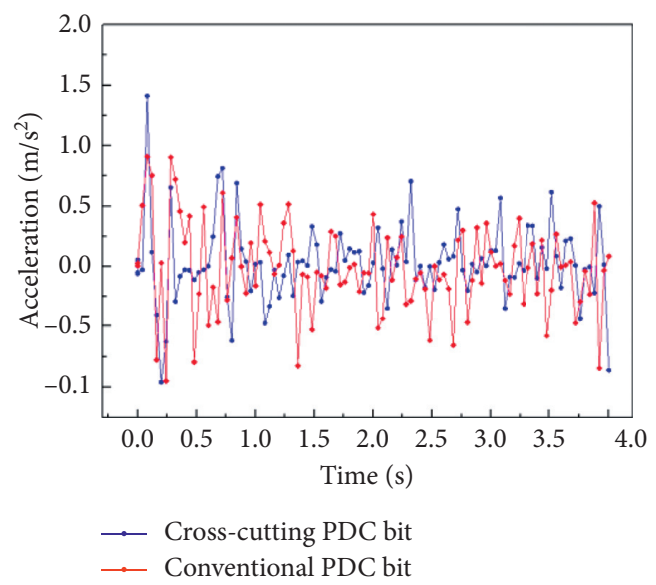

FIgURE 14: Acceleration response along the drilling direction.

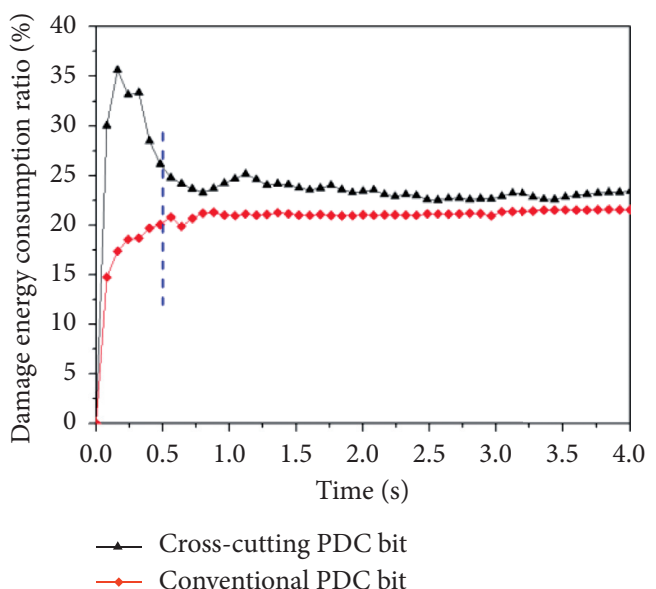

FIGURE 15: Damage energy consumption ratio in rock breaking.

such as deviation angle, rock characteristics, and WOB on the cross-cutting PDC bit-rock-breaking efficiency.

Drilling experiments were conducted with an 8.5 in diameter cross-cutting PDC bit and a conventional PDC bit. The experimental facility mainly included a bit experiment 


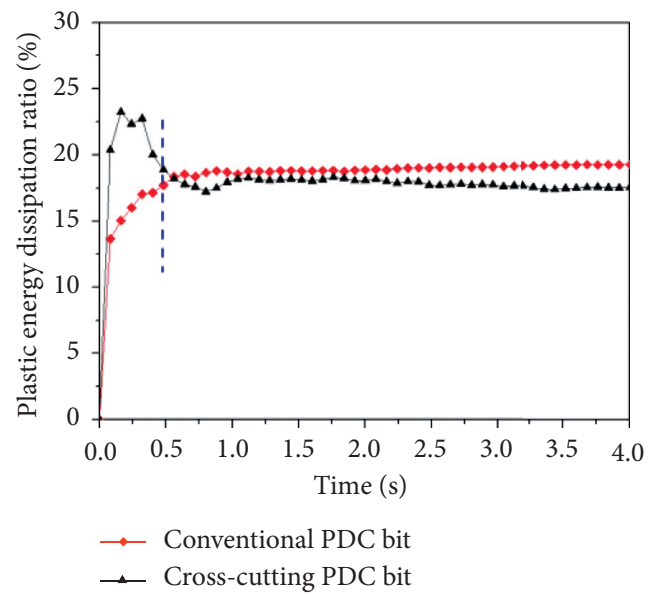

FIgURE 16: Plastic energy dissipation ratio in rock breaking.

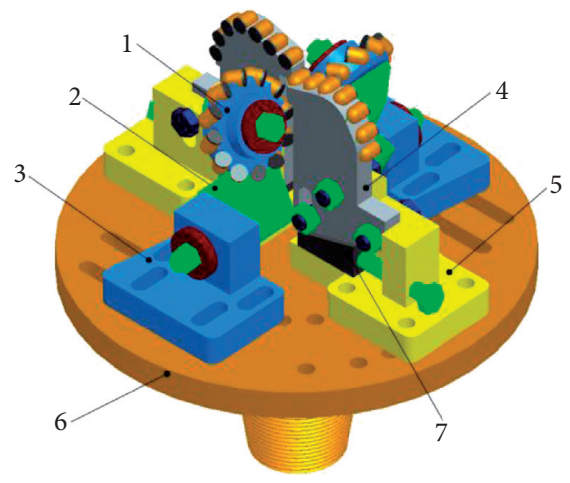

Figure 17: 3D model of the experiment bit.

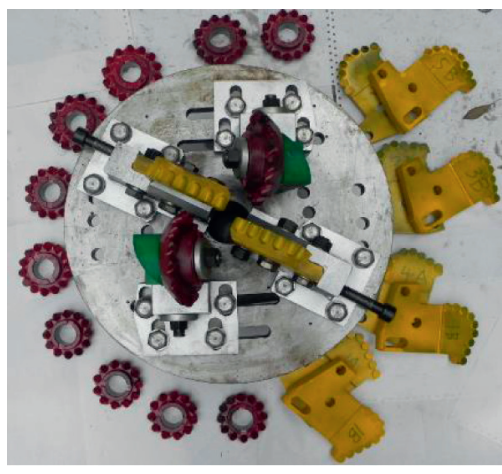

(a)

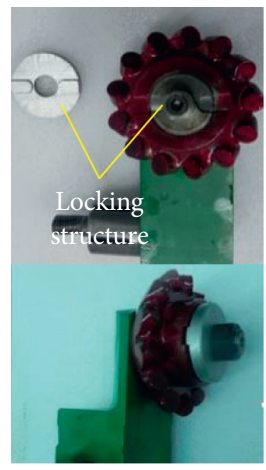

(b)

FIgURE 18: Structure of the experiment bit.

platform, a data acquisition system, and full-size bits with adjustable main parameters. The scraping-wheel of the experimental bit was stopped via a locking device, at which point it becomes a PDC bit of the same specifications (e.g., the platform and bit shown in Figure 19). The rock samples used were Wusheng sandstone and Beibei limestone. During the experiment, the bit was fixed onto the stem of the shelf, and the rock was affixed to a supporting device on the rotary table of the shelf. To facilitate testing and data collection, the rotation of the bit was substituted by the contrarotation of the table, and the rotating speed was set at $30 \mathrm{rpm}$.

5.3. Analysis of the Bottom-Hole Pattern. When the fixed cutting structure and scraping-wheel cutting structure jointly work in rock breaking, a retiform pattern forms. Figure 20 shows the bottom patterns of sandstone and limestone under a cross-cutting PDC bit. A cross-cutting 


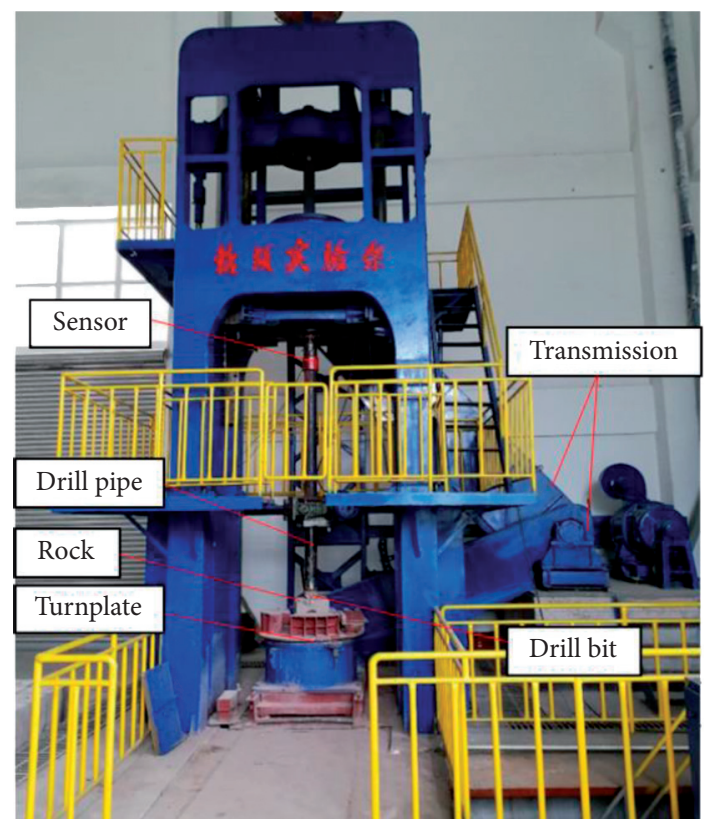

(a)
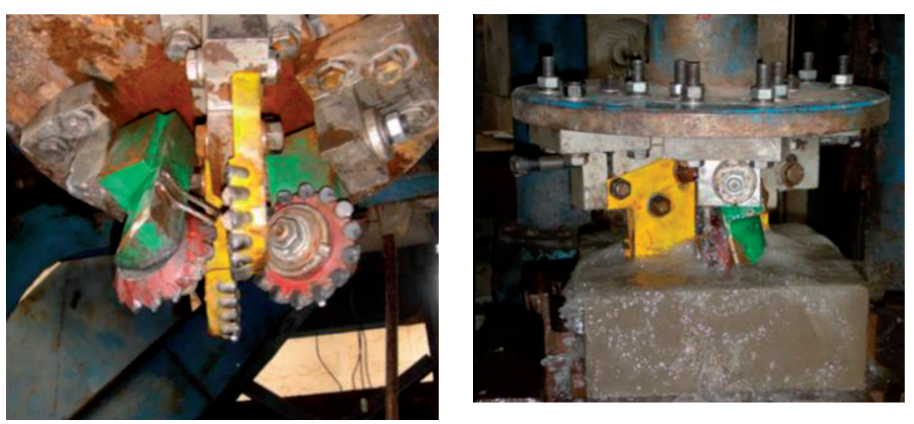

FIgURE 19: Experimental equipment.

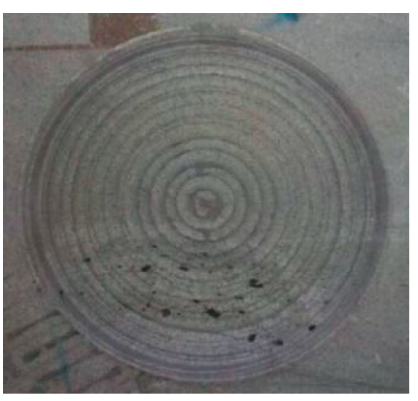

(a)

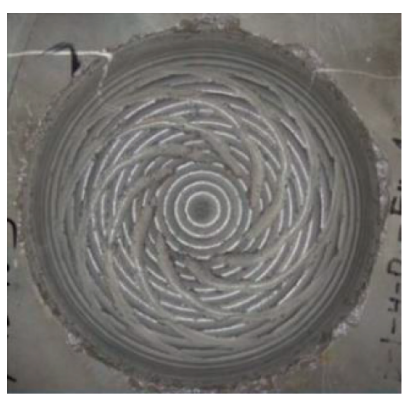

(b)

FIgure 20: Bottom-hole patterns of a different bit. (a) Conventional PDC bit. (b) Cross-cutting PDC bit.

PDC bit produces an obviously different bottom pattern than a conventional bit, and the uneven bottom free surface can facilitate penetration of the cutter and thus improve rock-breaking efficiency. The cross-cutting method of the new PDC bit can reinforce the penetration effect on the unbroken rock at the bottom hole, making it easier to damage the rock. Particularly, the tensile stress of the rock in the above-mentioned area is intensified, causing the rock to undergo brittle fracture failure when drilling in these areas. Figure 21 shows the bottom-hole generated by the novel bit under different deviation angles; inspection of the figure indicates that, as the deviation angle increases, the speed of the wheel cutter decreases, and the slip length of the cutting teeth increases.

Figures 22 and 23 show the debris produced by different bits for sandstone rock samples. The novel PDC bit produces larger rock debris than does the conventional bit. Large rock debris can improve energy utilization and rock-breaking efficiency. Simultaneously, the results are consistent with the simulation results, which verify the correctness of the simulation results.

Figures 24 and 25 show the WOB-ROP relationship and the WOB-torque relationship, respectively, of the mesh-like cutting PDC bit and the conventional bit [Supplemental files] (available here). The figures show that the penetration rates and torques of both bit types increase along with WOB. Under the same WOB, the mesh-like cutting PDC bit shows an approximately $20 \%$ higher rate at a slightly larger torque. Considering the uneven rock surface in the bottom-hole that is formed by the mesh-like cutting PDC bit, and the structure characteristics of the mesh-like cutting PDC bit, the invasive ability of the cutter is stronger, and the torque increases relatively with the increase of invasive depth. In the process of drilling, the cutters of the dynamic and static cutting structure break the rock by shearing. However, the mesh-cutting method enables stronger tensile stress where 


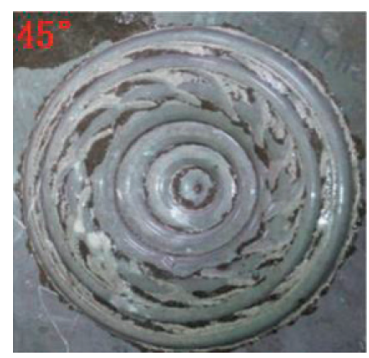

(a)

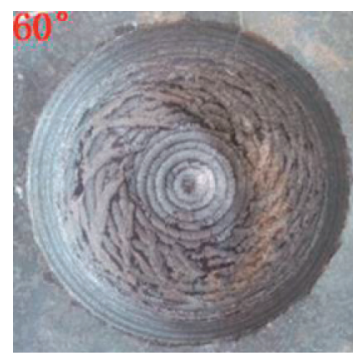

(b)

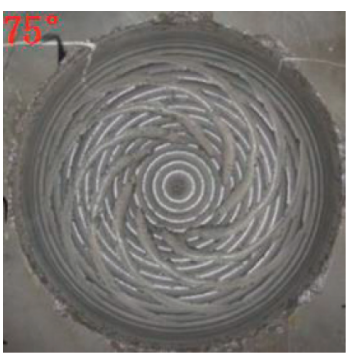

(c)

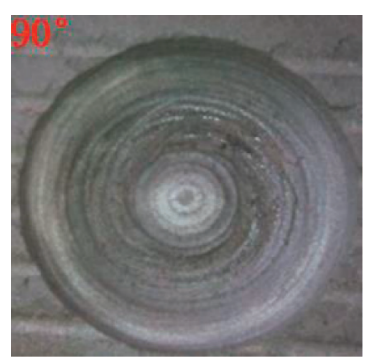

(d)

FIgURE 21: Bottom-hole generated by the novel bit under different deviation angles. (a) $45^{\circ}$, (b) $60^{\circ}$, (c) $75^{\circ}$, (d) $90^{\circ}$.

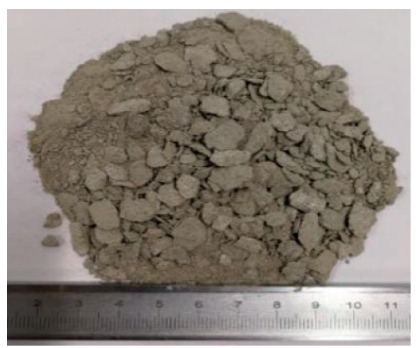

Figure 22: Conventional PDC bit.

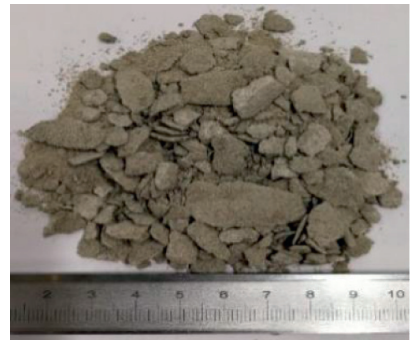

Figure 23: Novel PDC bit.

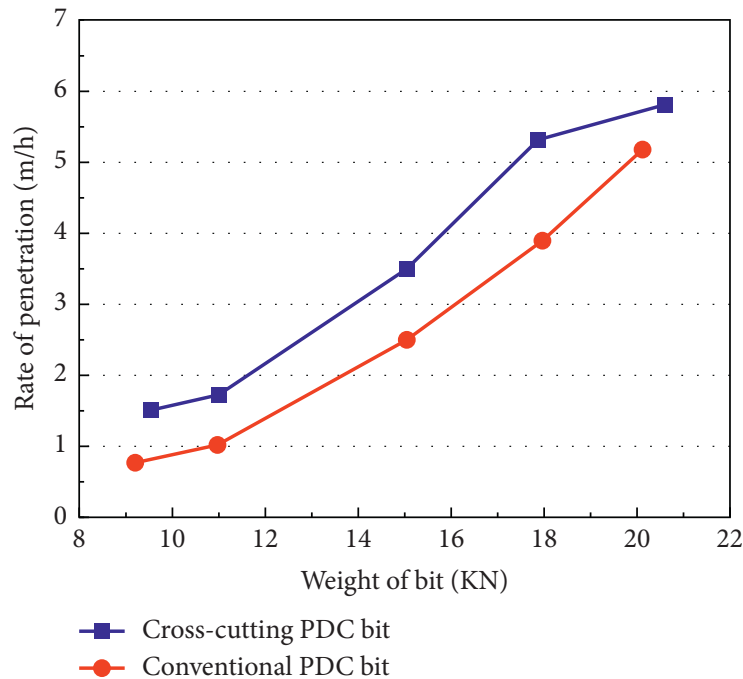

FIgURE 24: Relationship between WOB and ROP during drilling sandstone.

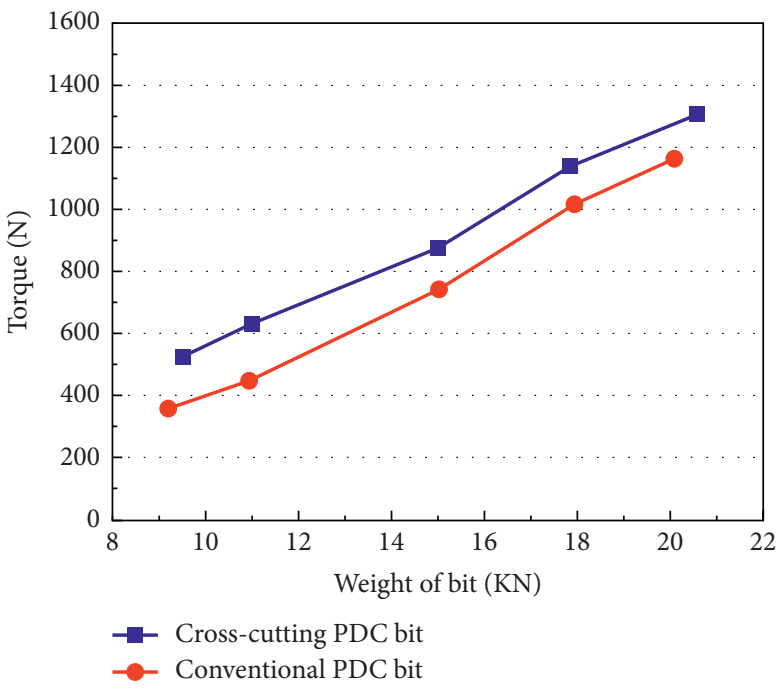

FIgURE 25: Relationship between WOB and torque during drilling sandstone.

the tracks intersect; when breaking these areas, a brittle fracture failure of the rock occurs to some extent. The meshlike cutting PDC bit, when breaking rock-including shearing and some fracture failure-shows higher efficiency than the conventional bit, which relies on the shearing method alone.

Figures 26 and 27 show, respectively, the WOB-ROP relationship and WOB-torque relationship of cross-cutting PDC and conventional bits when drilling in limestone [Supplemental files] (available here). Under lower WOB, neither cutter can effectively penetrate the rock, and the penetration rates of both types are low. As WOB increases, the cross-cutting bit exhibits an obvious higher rate than the regular one, with a maximum discrepancy of $48.8 \%$. When the cross-cutting bit drills into hard strata, it boasts two advantages: (1) The uneven bottom pattern caused by crosscutting facilitates the cutter in penetrating the strata and improves the efficiency. (2) Cross-cutting helps to concentrate stress, causing more microcracks and increasing the proportion of rock fracture failure. As a result, in comparison with the regular bit, the cross-cutting PDC bit has an advantage in breaking hard strata over soft strata.

Figures 28 and 29 show, respectively, the WOB-ROP relation and WOB-torque relations of cross-a cutting PDC 


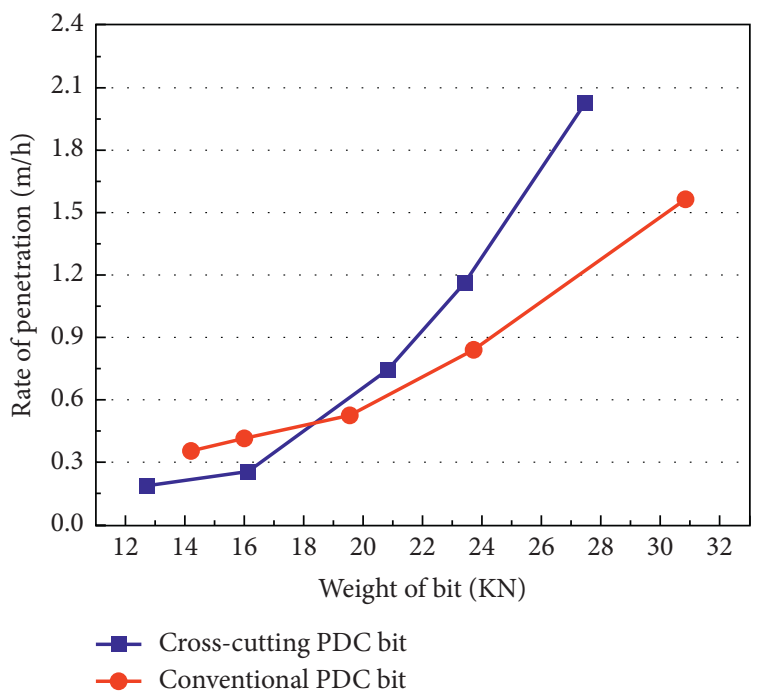

FIgURE 26: Relationship between WOB and ROP during drilling limestone.

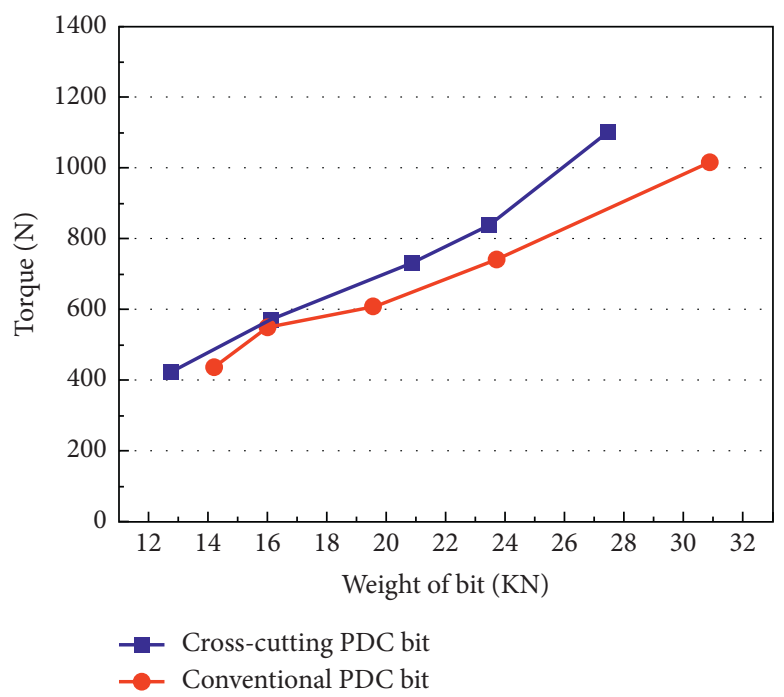

FIGURE 27: Relationship between WOB and torque during drilling limestone.

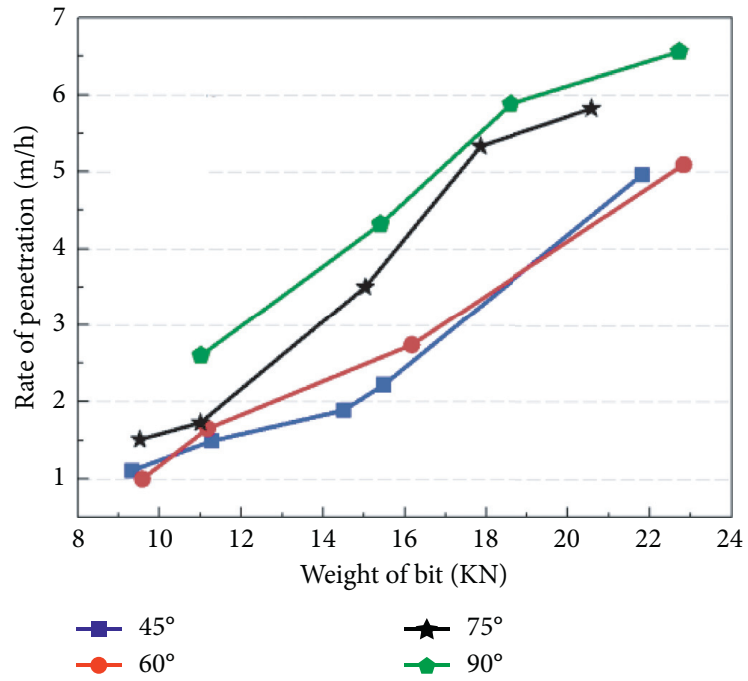

Figure 28: Relationship between WOB and ROP with $\alpha$ change of bits (sandstone). 


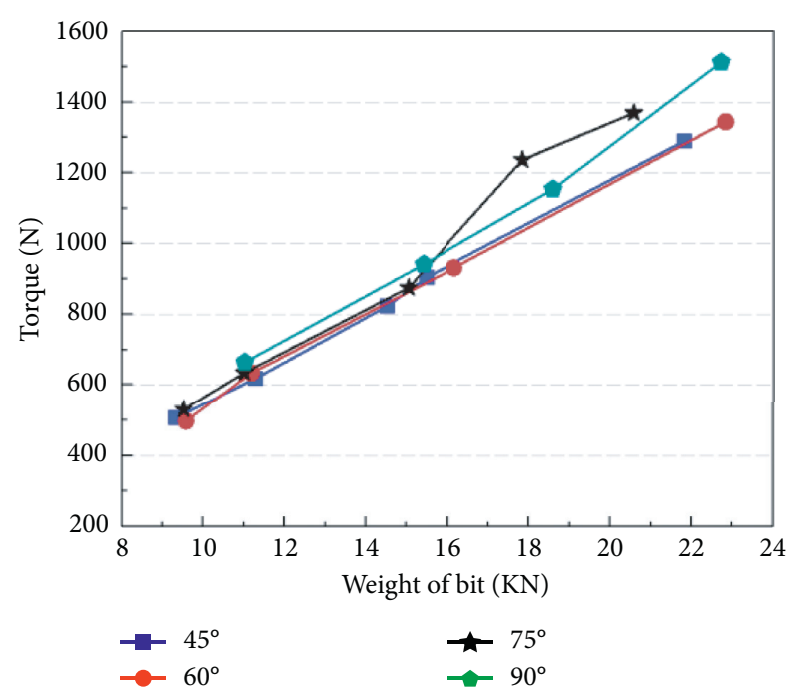

FIGURE 29: Relationship between WOB and torque with $\alpha$ change of bits (sandstone).

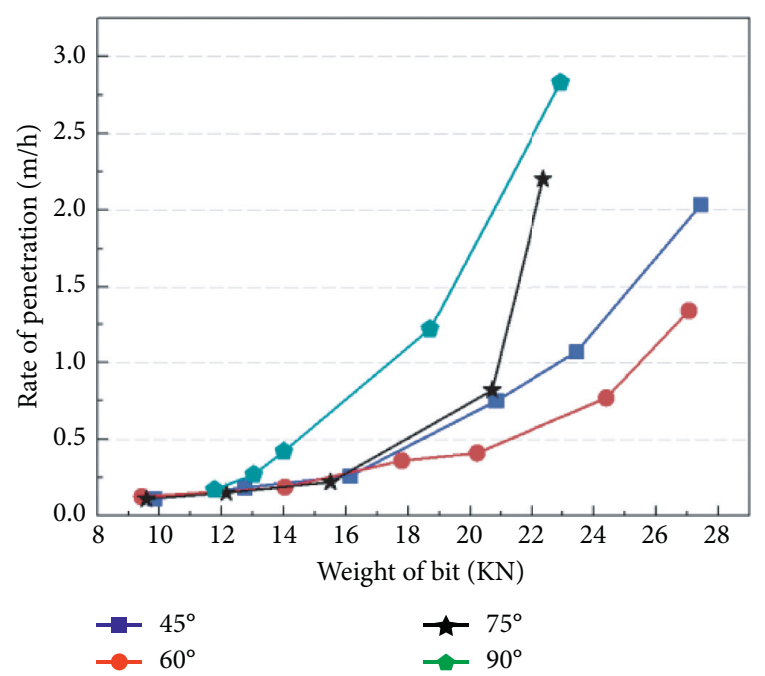

FIgUre 30: Relationship between WOB and ROP with $\alpha$ change of bits (limestone).

bit drilling in sandstone at different deviation angles [Supplemental files] (available here). From the figures, we can see that penetration rates increase along with WOB, and the same occurs for torques. Under a given WOB, the greater the deviation angle, the higher the ROP of the cross-cutting drilling bit with a slightly smaller torque amplification. However, when WOB is $>20 \mathrm{KN}$, ROP reaches a minimum at a deviation angle of $60^{\circ}$. Figures 30 and 31 show, respectively, the WOB-ROP relation and WOB-torque relations of the cross-cutting PDC bit drilling in limestone at different deviation angles. In the beginning, different deviation angles lead to basically the same penetration rates. However, along with the increase of WOB, the cutter begins to effectively penetrate the rock, and ROP increases rapidly. Under a given $\mathrm{WOB}$, the penetration rate basically increases along with the deviation angle, and the amplification of the

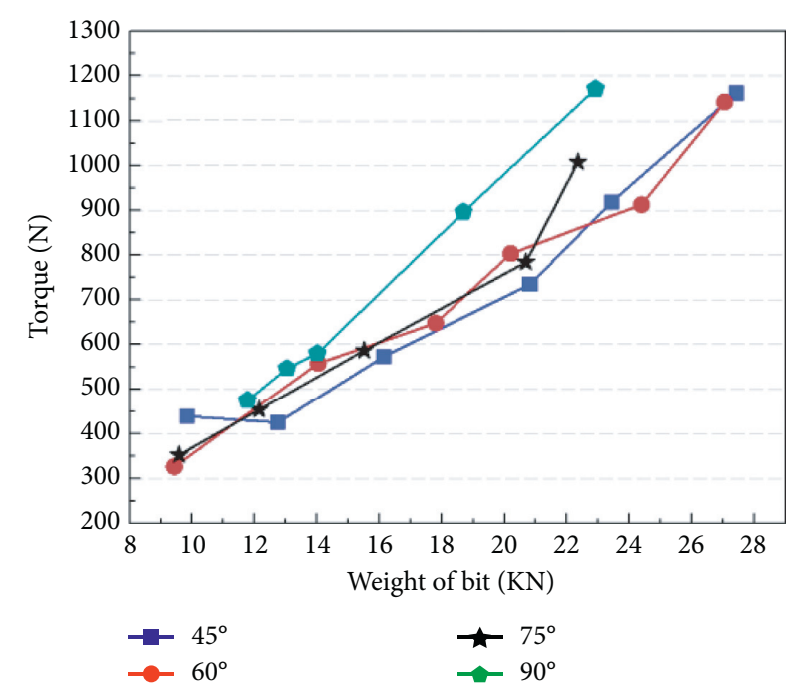

FIGURE 31: Relationship between WOB and torque with $\alpha$ change of bits (limestone).

torques remains small. The minimum value of the penetration rate appears at a deviation angle of $60^{\circ}$. Considering the characteristics of the cross-cutting bit, we know that the greater the deviation angle, the lower the rotation rate of the scraping wheel, and the greater the slippage of the cutter, which means a better cross-cutting effect and higher rockbreaking efficiency.

\section{Conclusions}

(1) The motion track equation of cross-cutting PDC bit was derived by using the compound coordinate system. Through the unit experiment and discrete element simulation of single-cutter cutting, the cutting force, volume-specific load, and crack propagation were analyzed under different cutting modes. The results show that cross-cutting is an efficient rock-breaking method saving both force and power.

(2) In the rock-breaking process, the cross-cutting PDC bit sets many rock elements under the condition of tensile stress and the plastic energy dissipation ratio of the novel PDC bit is lower while the damage energy consumption ratio is higher than that of the conventional bit, which is beneficial to increasing the ratio of fracture failure and improving rock-breaking efficiency. Analysis of the acceleration in the procedure of drilling shows the vibration of the crosscutting PDC bit is not large, which is conducive to prolong the service life of the bit.

(3) The drilling comparison experimental results show that the cross-cutting PDC bit forms a mesh-like bottom-hole pattern, which is in line with the theoretical analysis; the cross-cutting bit has a $20 \%$ higher penetration rate than the regular bit when drilling in soft strata and up to $48.8 \%$ higher when drilling in hard limestone; when drilling in hard 
rock, the cross-cutting bit exhibits a more obvious speed-up effect.

(4) With deviation angles being the same, when crosscutting PDC bit drilling, respectively, soft and hard rock, the rates and torques increase along with the pressure. Under a given WOB, when drilling in soft sandstone, the penetration rate increases along with the deviation angle, and the torque exhibits small amplification. When drilling in hard rock, the penetration rate basically increases with the deviation angle, but the minimum value appears at a deviation angle of $60^{\circ}$ and again the amplification of the torque is small. The experimental results show that the better offset angle range of the new bit is $70^{\circ} \sim 90^{\circ}$.

(5) The cutter load test of the new type bit is very valuable research. However, due to the limitation of experimental conditions, this article has not been completed. This is what we need to focus on in the next step.

\section{Data Availability}

The data used in the study are available from the corresponding author upon request.

\section{Conflicts of Interest}

The authors declare that there are no conflicts of interest regarding the publication of this paper.

\section{Acknowledgments}

This project was supported by National Natural Science Foundation of China, Grant no. 51374176, Scientific Research Starting Project of SWPU (no. 2019QHZ009), and China Postdoctoral Science Foundation (2020M673285).

\section{Supplementary Materials}

Experimental data of cross-scraping PDC bit. (Supplementary Materials)

\section{References}

[1] R. Q. Zuo, "International advancement of drilling bits for oil and gas well (3)-PDC bits progress and present trend," Exploration Engineering: Rock \& Soil Drilling and Tunneling, vol. 43, no. 4, pp. 40-48, 2016.

[2] Y. X. Yang and Y. C. Kuang, "New progress and development trend of rock breaking technology in oil and gas drilling," in Proceedings of the Tenth Petroleum Drilling Institute Director Meeting, pp. 154-160, Chengdu, China, June 2010.

[3] P. S. M. Dougherty, R. Pudjoprawoto, and C. F. Higgs, "Bit cutter-on-rock tribometry: analyzing friction and rate-ofpenetration for deep well drilling substrates," Tribology International, vol. 77, pp. 178-185, 2014.

[4] M. Amri, G. Pelfrene, L. Gerbauda, H. Sellami, and M. Tijani, "Experimental investigations of rate effects on drilling forces under bottom hole pressure," Journal of Petroleum Science and Engineering, vol. 147, pp. 585-592, 2016.
[5] K. A. Yu, "Experimental research on characteristics of hole reaming and side cutting of one-cone bits," Petroleum Science, vol. 5, no. 3, pp. 280-284, 2008.

[6] M. Yahiaoui, L. Gerbaud, J. Y. Paris, J. Denape, and A. Dourfaye, "A study on PDC drill bits quality," Wear, vol. 32, no. 41, pp. 298-299, 2013.

[7] L. Perneder, E. Detournay, and G. Downton, "Bit/rock interface laws in directional drilling," International Journal of Rock Mechanics and Mining Sciences, vol. 51, pp. 81-90, 2012.

[8] H. Seyed Ali and K. Shivakumar, "Influences of bit profiles on possible fracture modes," Petroleum Exploration and Development, vol. 44, no. 4, pp. 1-8, 2017.

[9] S. Negm, K. Aguib, V. Karuppiah et al., "The disruptive concept of $3 \mathrm{D}$ cutters and hybrid bits in polycrystalline diamond compact drill-bit design," in Proceedings of the SPE183335-MS, SPE Abu Dhabi International Petroleum Exhibition and Conference, pp. 1-10, Abu Dhabi, UAE, November 2016.

[10] M. Pak, M. Azar, S. Bits, and J. Pahl, "Conical diamond element enables PDC bit to efficiently drill chert interval at high ROP replacing turbine/impregnated BHA, SPE-178765-MS," in Proceedings of the SPE Drilling Conference and Exhibition Held in Fort World, pp. 1-3, Fort Worth, TX, USA, March 2016.

[11] J. Schilling, E. Cooley, M. Azar et al., "Innovative conical diamond element bit significantly reduces drilling cost of laterals, SPE-180499-MS," in Proceedings of the SPE Asia Pacific Drilling Technology Conference, pp. 22-24, Singapore, Singapore, August 2016.

[12] A. Wong, D. O. Bruce, J. J. Herman, S. Isnor, P. James, and R. Marley, "New hybrid bit technology provides improved performance in conventional intervals. SPE-181668-MS," in Proceedings of the SPE Annual Technical Conference and Exhibition, Dubal, UAE, September 2016.

[13] L. Chen, Y.-X. Yang, Y. Liu, M. Lin, C.-L. Zhang, and S.-W. Niu, "The operational theory and experimental study of scraping-wheel diamond bit," Journal of Petroleum Science and Engineering, vol. 156, pp. 152-159, 2017.

[14] J. Rojek, E. Oñate, C. Labra, and H. Kargl, "Discrete element simulation of rock cutting," International Journal of Rock Mechanics and Mining Sciences \& Mining Sciences, vol. 48, no. 6, pp. 996-1010, 2011.

[15] D. V. Swenson, D. L. Wesenberg, and A. K. Jones, "Analytical and experimental investigations of rock cutting using PDC Drag cutters," in Proceedings of the SPE 10l50, San Antonio, TX, USA, October 1981.

[16] D. H. Zeuch, D. V. Swenson, and J. T. Finger, "Subsurface damage development in rock during drag-bit cutting: observations and mode1 predictions," in Proceedings of the 24th US Symposium On Rock Mechanics, College Station, TX, USA, June 1983.

[17] J. T. Finger and D. H. Zeuch, "Rock breakage mechanisms with PDC cutter," in Proceedings of the SPE 14219, Las Vegas, NV, USA, September 1985.

[18] Y. Zhai, "Research on the theory and method of PDC bit design," Doctoral Dissertation, Petroleum University, Dehradun, Uttarakhand, 1990.

[19] Y. X. Yang and L. Chen, "Composite drill bit," US 8985243B2, 2015.

[20] Y. Yang, C. Zhang, L. Chen, and Y. Liu, "Kinematic and bottom-hole pattern analysis of a composite drill bit of crossscraping," Proceedings of the Institution of Mechanical Engineers, Part C: Journal of Mechanical Engineering Science, vol. 231, no. 17, pp. 3104-3117, 2016. 
[21] J. Rojek, E. Oñate, C. Labra, and H. Kargl, "Discrete element simulation of rock cutting," International Journal of Rock Mechanics and Mining Sciences \& Mining Sciences, vol. 48, no. 6, pp. 996-1010, 2011.

[22] W. Liu, X. Qian, T. Li, Y. Zhou, and X. Zhu, "Investigation of the tool-rock interaction using drucker-prager failure criterion," Journal of Petroleum Science and Engineering, vol. 173, pp. 269-278, 2019.

[23] M. C. Jaime, Y. Zhou, J.-S. Lin, and K. Gamwo, "Finite element modeling of rock cutting and its fragmentation process," International Journal of Rock Mechanics and Mining Sciences, vol. 80, pp. 137-146, 2015.

[24] S. Liu, H. Chang, H. Li, and G. Cheng, "Numerical and experimental investigation of the impact fragmentation of bluestone using multi-type bits," International Journal of Rock Mechanics and Mining Sciences, vol. 91, pp. 18-28, 2017.

[25] Q. F. Wang, "Study on rock breaking simulation of singlecone bit," Vibration and Shock, vol. 29, pp. 108-112, 2010. 